\title{
Emotional Intelligence and Anxiety among Under Graduate Students
}

\author{
Sapnali Nayak ${ }^{1 *}$, Dr. R Krishnan Bhatt ${ }^{2}$
}

\section{ABSTRACT}

In the present study, the researchers have attempted to assess the relationship between emotional intelligence and anxiety among undergraduate students of Assam, India. The tool which was used to assess emotional intelligence was Schutte Self Report Emotional Intelligence Test (SSEIT 2009) and for anxiety, the Beck Anxiety Inventory (1988). The sample includes 117 young adults, 50 boys and 67 girls. The study found that there was no significant relationship between emotional intelligence and anxiety. The study also suggested that there was no significant relationship between boys and girls with respect to emotional intelligence, but there was a significant relationship between boys and girls with respect to anxiety.

\section{Keywords: Emotional intelligence, Anxiety, UG students}

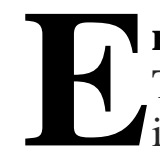

\section{motional intelligence}

The concept Emotional Intelligence (EI) refers to the processes which involved identifying, applying, understanding, and controlling the emotional states of one's own and others to overcome emotional issues and to influence actions (Mayer \& Salovey, 1997; Salovey \& Mayer, 1990). In addition to general intelligence which focuses on cold cognitive processes, EI functions on "hot" cognitive-emotional processes that are important to the person and the environment (Abelson, 1963). Emotions are an internal mechanism that is the most important thing in human life, emotions are highly associated with feelings. Emotion determines an individual and often shapes the world of the person around him. Etymologically, emotions are a state of feeling about some external event or thing that includes cognitions, biological changes and communication or actions. This contributes to unusual actions in life as we suppress our emotions. So, it is very necessary to express the feeling for our well-being. But it is very difficult and important to express the emotions at the right time, at the right place, to the right person and up to proper degree. It is the ability to understand one's own emotions and that of others, to deal effectively with them; more specifically it is called as 'emotional intelligence'. Emotions form our thinking processes and thus impact our decision-making capability. According to Birch (1995), feelings are the most important thing in life. Emotional intelligence is an individual's ability to be conscious

\footnotetext{
${ }^{1}$ Research Scholar, Department of Psychology, Kristu Jayanti College (Autonomous), Bangalore, India

${ }^{2}$ Assistant Professor, Department of Psychology, Kristu Jayanti College (Autonomous), Bangalore, India *Corresponding Author
} cited. 
of his or her emotions and feelings and those of others and to use this information in relationships, at school, at work to facilitate progress rather than roadblocks.

In order to self-motivate and to build positive social interactions, emotional intelligence helps one to understand and manage our emotions; it is first steps in understanding our true potential. In terms of personal, academic and professional success, the importance and advantages of EI are vast.

\section{Anxiety}

Anxiety is a feeling of fear or is the fear about the things and events that are yet to happen; anxiety is a common feeling that is encountered from time to time by everyone. Nowadays, anxiety is very common and people experience anxiety to some extent on a daily basis. The word anxiety is used in everyday contexts to describe anxious and negative emotions encountered by people when they are in demanding or worried situations. Fear is an emotional response to an immediate danger and is often associated with a reaction to fight or flight-either remaining to fight or moving to avoid fear. In addition, anxiety may be triggered in response to specific situations, people or event, as well in anticipation of an event. There are different explanations provided by experts about the anxiety phase. According to May (1950) anxiety is a fear alert by a danger to a value that individual holds important to his existence as a personality. Spielberger (1972) stated that anxiety is an emotional activity which has four components and they are phenomenological, physiological, task performance, and the conditions under which anxiety is increased or decreased. According to Nijhawan (1972), anxiety is one of the most pervasive psychological conditions which is triggered by internal conflicts. Its natural role is to alert us to possible threats, enabling us to properly assess them and respond to them. Anxiety is one of the most common mental health conditions in the United Kingdom and elsewhere, but it is under-reported.

\section{Relationship between emotional intelligence and anxiety}

Emotional intelligence encourages us to deal with the challenges we have encountered in our lives. And anxiety is a feeling of fear, which we experience when we encounter those challenges. Emotional intelligence provides us the ability to deal effectively with the anxiety which we experienced. Emotional intelligence helps us to control emotions such as fear, anxiety and stress. Emotional intelligence means empathy, compassion, motivation and the capacity to respond to external pain appropriately. By developing emotional intelligence one can become more productive and successful at what one does. The process and result of emotional intelligence development also consists of many elements known to lower stress and anxiety for individuals.

\section{Anxiety and Young Adults}

Anxiety is a feeling of excessive fear, which is very frequently experienced by the young adults. It may be excessive worries about college work, peers or any extra activities; they may experience anxiety maybe because of extra load of assignments, deadline of submitting assignments, exam fear etc. It is estimated that anxiety disorders affect $3.3 \%$ of children and young adults in the UK (about 290,000) and while we cannot be sure whether children and young adults are more anxious today than past generations, mental health issues are remarkably common in young people, disabling and operating a lifelong course. (creswell et al., 2010; Hagell et al, 2013). Fear of examinations, group gathering and much more can become the causes of anxiety and can contribute to social phobia often. The expectation from peers and parents are also a factor why anxiety is thought to be the cause. The 
expectation which is set by the parents from their children and when those expectations are not met, that can result in anxiety.

\section{Need and significance of the study}

Emotional Intelligence plays a major role in one's life. It helps us to build stronger relationships, become successful in our life such as in work, academic, personal goals etc. Emotional intelligence provides us the potential to cope with stress and anxiety effectively, which helps an individual to solve difficult situations. As college students come across different obstacles in their life, emotional intelligence will help them to connect with their feelings and turn those feelings into actions and allow them to make decisions. For a successful adulthood, one of the important key points to consider in developing the skills is emotional intelligence that supports a range of development and awareness. In this generation where young adults face certain situations where they may experience stress or anxiety, in such situations emotional intelligence will help them to manage their emotions in a positive way to relief stress, interact effectively, resolve obstacles and diffuse conflict.

There are studies conducted on the topic to find the relationship between emotional intelligence and anxiety in adolescents, adulthood etc., however there aren't many studies based on young adults. I consider this study as an opportunity to make awareness among the young adults to know about their emotions and also the emotions of others and to understand the situation and overcome challenges and also help them to cope with the anxiety they experience. This present study is an attempt to find out the relationship between emotional intelligence and anxiety among UG students of Assam. The other interests of the study were to find out the influence of gender on emotional intelligence and anxiety. Thus, the study on emotional intelligence and anxiety is very relevant and important.

\section{REVIEW OF LITERATURE}

According to Connor et al.; (2009) did a study on emotional intelligence, anxiety and resiliency, according to the study the above variables are based on academic concerns because the literature review of the study indicates that academic achievement improves or deteriorates in the presence or lack of characteristics related to these variables. This study, used the Mehrabian's (2001) General Emotional Intelligence Scale (GEIS); Spielberger's State- Trait Anxiety Inventory; Connor's (after wolin\& 1993) Resiliency Scale. The finding of this study says that for emotional intelligence and anxiety there exist a negative and significant relationship between the variables.

Pablo fernandez- Berriocal et al.; (2006) conducted a study on the role of emotional intelligence in anxiety and depression among adolescents. Pablo did a study on Two hundred and fifty high school students. Pablo used the Trait Meta-Mood Scale (TMMS) this scale used to measure the Emotional intelligence and it is one of the most widely used selfreport measures, also used the State trait anxiety inventory (STAI) to assess Anxiety. This present study revealed two main findings. From the findings we got to know that selfreported emotional intelligence was negatively related to levels of anxiety.

A research done by Sajad Ahmad Bhat et al.;(2017) on the relationship of emotional intelligence with anxiety among students. Anxiety is a feeling of fear people may experience different kinds of anxiety in different situations. And emotional intelligence will help us to deal with our stress and anxiety. The tools which were used in the present study were Schutte Self-Report Emotional Intelligence Test (SSEIT 1998). And to assess anxiety Beck's Anxiety Inventory was used. There was total 60 students from Aligarh Muslim 
University. The collected data was analyzed by correlation and t-test with the help of SPSS. This present study reveals that there exists a negative correlation within the emotional intelligence and gender and the finding also revealing that there is no significant difference within level of anxiety across gender with males scoring moderately higher than females. According to the study the students who are high on the dimensions of emotional intelligence exhibit more maturity in stressful situation than the students who exhibit low on emotional intelligence thus they experience less anxiety.

According to Vargha Mokhlesi et al.; (2020) did a study of emotional intelligence, anxiety and gender among children. The present study was conducted on 100 children, 50 boys and 50 girls. The tools which were used in this present study are Multifactor Emotional Intelligence Scale-2004 (MEIS) of Shanwal which was used to measure the emotional intelligence. To measure anxiety the State-Trait Anxiety Inventory for children by Speilberger was used. The collected data was analyzed using different statistical techniques such as mean, standard deviation, t-test and person's product moment correlation of coefficient significance through SPSS. The result exhibit that in state anxiety as well as in trait anxiety the boys and the girls do not differ significantly; they experience similar state and trait anxiety levels. The study also exhibits that among children the state anxiety is related with trait anxiety. And the result of the present study found to be beneficial to teachers, parents and students.

According to Mashhadi Ali et al.; (2011) conducted a study on the relationship between emotional intelligence and its components with symptoms of anxiety. It was a descriptive and correlation research study. A sample of 184 masters students were taken, which falls under three groups; humanities, technical-engineering and basic science. The tools which were used in the present study are Trait Meta Mood Scale (TMMS) which was used to assess the emotional intelligence and anxiety symptoms and Beck Anxiety Inventory (BAI). The findings of the study reveal that there was a significant reverse relationship between the general scores of emotional intelligence and anxiety symptoms. And various regression analysis displays that clarity of feelings and emotional restore could predict anxiety symptoms. It was concluded therefore that; emotional intelligence is reversely related to symptoms of anxiety.

Since not many studies have been conducted on emotional intelligence and anxiety among undergraduate students, so in order to increase the understanding of this topic, the present study recruited a sample of undergraduate students from Assam, India to assess the relationship between their emotional intelligence and anxiety levels.

\section{METHODOLOGY}

\section{Statement of the problem}

As UG students experience many difficult circumstances in their lives. It's necessary to think about their mental health and also about their emotions. The students may experience exam anxiety to adjustment problem at the universities or colleges; anxiety has an adverse effect on the performance and mental health of the students. Emotional intelligence, on the other hand, allows one to cope with college anxiety. Therefore, it is important to have high emotional intelligence so that the students can experience less anxiety. The students who have high emotional intelligence are good at understanding consequences of negative emotions and overall relationships of their life. So, it is important for young adults to be highly emotionally intelligent, because being highly emotionally intelligent can help them in many ways. It helps them to overcome various obstacles which they faced. 


\section{Objectives}

- To study the relationship between emotional intelligence and anxiety among UG students.

- To study if there is difference between boys and girls on emotional intelligence.

- To study if there is difference between boys and girls on anxiety.

\section{Hypotheses}

H1: There will be no significant relationship between emotional intelligence and anxiety.

H2: There will be no significant difference between boys and girls with respect to emotional intelligence.

$H_{0} 3$ : There will be no significant difference between boys and girls with respect to anxiety.

\section{Design of the study}

A descriptive non experimental research design was employed using quantitative approach to assess the relationship between emotional intelligence and anxiety and to find out the gender difference with respect to emotional intelligence and anxiety among undergraduate students.

\section{Sample}

The sample of the study comprised of 117 UG students of age group 18-25 years, of which there were 50 boys and 67 girls studying in various colleges of Assam, India, selected using purposive sampling technique.

\section{Tools Used}

- Emotional Intelligence was measured by using Schutte Self Report Emotional Intelligence test which was developed by Schutte, N.S., Malouff, J.M. and Bhullar in (2009). It's a self-report inventory which has 33 items ranging from $1=$ (strongly disagree), $2=$ (disagree), $3=$ (neither disagree nor agree), $4=$ (agree), $5=($ strongly agree) with Cronbach's alpha .90. Test-retest (two-week) reliability of .78. In this questionnaire the item 5, 28 and 33 were reversed.

- Anxiety was measured by Beck Anxiety Inventory developed by Beck in 1988. Beck Anxiety Inventory (BAI) is a self-report questionnaire, it is 21 item scale with ranging from -0 (Not at all), $1=$ (Mildly), $2=($ Moderately), $3=($ Severely $)$ with Cornbach's alpha value is.92, test retest (1week) reliability is .75.

\section{RESULT AND DISCUSSION}

The study intended to analyse the relationship between Emotional intelligence and Anxiety among Under Graduate students of the age group 18-25.

Table 1 Mean and Standard deviation of emotional intelligence and anxiety among undergraduate students

\begin{tabular}{|l|l|l|l|}
\hline & N & M & SD \\
\hline Emotional Intelligence & 117 & 125.19 & 11.979 \\
\hline Anxiety & 117 & 22.68 & 13.457 \\
\hline
\end{tabular}

The table 1 shows the Mean and Standard Deviation of Emotional Intelligence which was 125.19 and 11.979 respectively. The mean and standard deviation of anxiety was 22.68 and 13.457 respectively. Emotional intelligence has higher mean than anxiety but the deviation 
of scores for anxiety is more among the undergraduate's students than emotional intelligence.

Table 2 Correlation between emotional intelligence and anxiety among undergraduate students

\begin{tabular}{llll}
\hline & $\mathbf{N}$ & rho & P \\
\hline Emotional Intelligence and Anxiety & 117 & -.104 & .266 \\
\hline
\end{tabular}

An analysis of the above table indicates that there were 117 under graduate students. In order to see whether there was any significant relationship between emotional intelligence and anxiety among under graduate students, the scores were subjected to spearman correlation test, which yielded the spearman correlation coefficient ' $r$ ' as -.104, which was statistically insignificant at both the levels. Therefore, the null hypothesis was accepted which means there was no significant relationship between these two variables. This finding can be supported by a study done by Aroline K. Tom et. al., 2017 who found there was a negative correlation between emotional intelligence and test anxiety among adolescents.

Table 3 Comparing emotional intelligence among boys and girls

\begin{tabular}{lllll}
\hline & $\mathbf{N}$ & $\mathbf{M}$ & $\mathbf{U}$ & $\mathbf{p}$ \\
\hline Boys & 50 & 62.57 & \multirow{2}{*}{1496.500} & .325 \\
Girls & 67 & 56.34 & & \\
\hline
\end{tabular}

An analysis of the above table indicates that there were 117 under graduate students among which 50 were boys and 67 were girls. The mean score of the boys on emotional intelligence was found to be 62.57 while for girls was 56.34, which indicates that the boys had a higher emotional intelligence levels than girls. In order to test the obtained mean difference for their statistically significance, the scores were subjected to Mann-Whitney U test and it was found to be 1496.500 which was statistically insignificant at both the levels. Thus, the null hypothesis was accepted which means that there was no significant gender difference in emotional intelligence among them.

Table 4 Comparing anxiety among boys and girls

\begin{tabular}{lllll} 
& $\mathbf{N}$ & $\mathbf{M}$ & $\mathbf{U}$ & $\mathbf{p}$ \\
\hline Boys & 50 & 48.25 & \multirow{2}{*}{$1137.500^{* * *}$} & .01 \\
Girls & 67 & 67.02 & & \\
\hline
\end{tabular}

An analysis of the above table indicates that there were 117 under graduate students among which 50 were boys and 67 were girls. The mean score of the boys on anxiety was found to be 48.25 , while that for girls was 67.02 , which indicates that the girls had a higher anxiety level than boys. In order to test the obtained mean difference for their statistically significance, the scores were subjected to Mann-Whitney $U$ test and it was found to be 1137.500 which was statistically significance at 0.01 levels. Therefore, the null hypothesis was rejected. It means there was a significant difference in anxiety among under graduate students.

\section{SUMMARY AND CONCLUSION}

The purpose of the research was to study the relationship between the emotional intelligence and anxiety among UG students. The research was conducted by distribution of two sets of questionnaires the Schutte Self Report Emotional Intelligence Test (SSEIT) for the 
Emotional intelligence and Beck Anxiety Inventory (BAI) for the anxiety. The sample involved 117 UG students in the age group of 18 to 25 years out of which 50 were boys and 67 were girls. The spearman correlation, Mann Whitney U test was used to evaluate the data.

\section{CONCLUSION}

- The results interpreted showed that there was no significant relationship between emotional intelligence and anxiety among UG students.

- Also, this study showed there was no significant difference in emotional intelligence between boys and girls among UG students.

- However, the study showed there was a significant difference in Anxiety between boys and girls among UG students.

\section{Limitation of the Study}

This study has the following limitations:

- As the sample was taken from a particular state it cannot be generalized to the whole of India.

- The study was only based on Under Graduate students therefore the emotional intelligence and anxiety level among other parts of the population cannot be taken into consideration.

- Participants had to fill the questionnaire online through Google forms. This could have affected the concentration of participants resulting in inaccurate responses.

\section{Implications}

The amount of anxiety among under graduate students have been found to be moderate. In order to deal with the anxiety levels of the students, the college can make some arrangements for stress management programmes which would help them in coping up with their anxiety level, because it has been seen that when students have anxiety and depression that gets unnoticed, their mental health is at risk which may lead to various behavioral and social problems, poor performance in studies, and low self-esteem. Also, the parents can help their children to deal with anxiety by providing them emotional support and finding them the right professional help when required.

And in order to improve the emotional intelligence of the students the college can arrange some emotional intelligence workshops and trainings which would help the students to create a greater self-awareness, self-control among them. It would also help them to grow as a person, increase resilience and decision-making capabilities and empathize with others.

\section{REFERENCES}

Bhat, S. A., \& Farooq, T. (2017). The relationship of emotional intelligence with anxiety among students. International Journal of Trend in Scientific Research and Development, Volume-1(Issue-6), 1216-1219. https://doi.org/10.31142/ijtsrd5778

Cejudo, J., Rodrigo-Ruiz, D., López-Delgado, M. L., \&Losada, L. (2018). Emotional intelligence and its relationship with levels of social anxiety and stress in adolescents. International Journal of Environmental Research and Public Health, 15(6), 1073.

Connor, B., \&Slear, S. (2009). Emotional intelligence and anxiety; Emotional intelligence and resiliency. International Journal of Learning, 16(1). 
Ehsan, D., \& Ehsan, D. (2014). The effect of anxiety and emotional intelligence on students' learning process faculty of human ecology. Journal of Education \& Social Policy, $1(2), 115-122$.

Fernandez-Berrocal, P., Alcaide, R., Extremera, N., \& Pizarro, D. (2006). The Role of Emotional Intelligence in Anxiety and Depression among Adolescents. In Individual Differences Research (Issue 1). www.idr-journal.com

Kamran, W., \& Fatima, I. (2013). Emotional intelligence, anxiety and procrastination in intermediate science students. Pakistan Journal of Social and Clinical Psychology, 11(2), 3.

Mayer, J. D., Salovey, P., \& Caruso, D. R. (2000). Models of emotional intelligence. RJ Sternberg (Ed.).

Sunil, K., \&Rooprai, K. Y. (2009). Role of emotional intelligence in managing stress and anxiety at workplace. Proceedings of ASBBS, 16(1), 163-172.

Tom, A. K., \&Ansia, A. (2017). Test anxiety and emotional intelligence among adolescents. Indian Journal of Positive Psychology, 8(3), 328-332.

Zysberg, L., Kelmer, G., \&Mattar, L. (2019). Emotional Intelligence, Attachment and Satisfaction with Romantic Relationships among Young Adults: A Brief Report. Psychology, 10(05). https://doi.org/10.4236/psych.2019.105044

\section{Acknowledgement}

The author(s) appreciates all those who participated in the study and helped to facilitate the research process.

\section{Conflict of Interest}

The author(s) declared no conflict of interest.

How to cite this article: Nayak S. \& R Krishnan Bhatt (2021). Emotional Intelligence and Anxiety among Under Graduate Students. International Journal of Indian Psychology, 9(2), 781-788. DIP:18.01.083.20210902, DOI:10.25215/0902.083 